\title{
How to Effectively Improve NCO Students' Wartime Equipment Repair Capability
}

\author{
Dapeng Tong ${ }^{1, a^{*}}$ and Yuanzhe $\mathrm{Xu}^{1, \mathrm{~b}}$ \\ ${ }^{1}$ No.1, Huayuan Road, Changchun City, Jilin Prov. China 130117 \\ a tdp_mail@sohu.com, ${ }^{\mathrm{b}}$ 328625400@qq.com
}

Keywords: Wartime equipment rush repair; Sergeant education; Virtual maintenance

\begin{abstract}
With the rapid development of armored equipment, the battlefield environment is becoming more and more complex, and the rate of battle injuries is increasing. How to make the battle injured equipment continue to enter the battle quickly and efficiently, that is, the ability to rush to repair the equipment in wartime becomes an important duty of non-commissioned officers. So how to effectively improve the ability of non-commissioned officers to rush to repair the equipment in wartime becomes a non-commissioned professional technology. In view of the characteristics and purposes of the rush repair of equipment in wartime, this paper puts forward some suggestions and considerations from three aspects: cultivating the officers'ability to detect high-efficiency faults, restoring equipment quickly, and adapting to the battlefield environment. Guiding significance.
\end{abstract}

\section{Concept and characteristics of equipment rush repair in wartime}

Concept of equipment repair in wartime. Emergency repair of equipment in wartime refers to a series of activities to rapidly restore the combat effectiveness of equipment by using emergency diagnosis and repair technology in battlefield. Its fundamental purpose is to make equipment continue to fight and win in battlefield.

Characteristics of equipment repair in wartime. First, time is pressing. Local warfare under the condition of informationization has the characteristics of large battle space, large battlefield changes and high rate of equipment damage. Quick is the basic requirement of modern warfare for rush repair of wartime equipment, requiring repair work to be within a reasonable time limit of tactics. Second, the environment is harsh, in wartime, because of the enemy's blockade, the logistics supply line may be cut off, coupled with the maintenance of resources consumption, while equipment is difficult to transport to the battlefield, easy to cause lack of equipment, may not be able to use replacement repair.

\section{Basic purpose of equipment repair in wartime}

Diversity of allowable state recovery . Because it is in a wartime state, equipment repair can allow diversity, not requiring the restoration of the original face of the equipment, but requiring it to be able to restore as soon as possible to complete a certain operational task in the state of work, or even as long as it can save itself, specifically:

1.To complete all operational tasks: to achieve normal repair state;

2.Can fight: Although the performance level has been reduced, but this time still can meet most of the task requirements;

3.To combat emergency: to carry out a specific combat task;

4.Be able to save themselves: enable the equipment to recover the appropriate maneuverability so as to be able to evacuate the battlefield.

The repair method should be flexible. Considering the shortage of equipment and equipment and the bad environment, the emergency repair in situ in battlefield should be different from that in peacetime. It is an emergency repair method adopted in a short time. Some non-standard repair techniques can be adopted, even some "temporary" methods can be used to ensure the recovery of war-damaged equipment in the shortest time. Restore basic functionality, quickly put into combat, 
such repair methods can be flexible and diverse, repair results can also be more optional.

\section{Reflections on ways and means of training NCO's wartime equipment rush repair capability}

Highlight "fast" and "accurate". With the continuous development of informationization construction of armored mechanized forces, new armored equipments have been put on the armored forces one after another. These new armored equipments have strengthened their functions, become more complex in structure, and become more and more integrated. Their fault mechanism, fault diagnosis and removal methods are more dependent on new technologies and new methods. Maintenance personnel should have the ability of "fast" and "accurate" fault detection based on maintenance testing equipment. To integrate this requirement into the professional and technical education of non-commissioned officers means that effective methods suitable for the army conditions should be summed up according to the new technology of equipment development, and practical teaching and training should be vigorously carried out. NCO's ability to repair equipment in wartime.

For example, sensors play an increasingly prominent role in the new armored vehicles, which is an important part of the vehicle integrated electronic system. Their functions and performance directly affect the combat performance of the whole vehicle, making its performance detection, fault location and prediction very important. Because the position of many sensors in the car body is very hidden, invisible, difficult to touch, difficult to detect whether the sensor is good or bad, which leads to fault location is very difficult, maintenance and support difficult, at the same time, the new equipment used on the sensor variety, function, principle and structure are also very different, fault The phenomenon and the reason are different, the traditional way can not sort out the law of each fault, which brings blindness to maintenance and support.

In view of this kind of actual situation, our school teacher has explored the effective fast fault location method which suits the army condition. Firstly, the circuit connection relation of the sensor in the equipment is defined. Secondly, the electric parameter signal characteristic of each sensor is measured in the actual vehicle when it is working normally. Each sensor transforms the vehicle condition information. Electric signals have a characteristic range or a characteristic value, or resistance or voltage, which should be distinguished according to the working principle of the sensor. Finally, in the corresponding jack to measure the electrical parameters of the sensor signal characteristics, if not within the range, the sensor can be replaced; if within the range, then the transmission Sensilla has no fault, it can judge other links. This method has been proved by practical teaching, which greatly improves the diagnostic efficiency of the cadets in this area and speeds up the generation of the cadets'ability to rush to repair equipment in wartime.

Carrying out equipment maintenance training combined with "simple measures". Emergency repair of equipment in wartime is usually carried out by means of emergency maintenance cabin, mobile portable maintenance equipment and so on. Emergency repair of equipment in situ and original parts is mainly completed by a single soldier or equipment operator, and manual maintenance tools are used to repair the damaged parts quickly without disintegration. That is to say, the emergency repair of equipment in wartime is to a great extent facing the condition of "shortage of equipment, equipment and personnel". Therefore, in the process of training sergeants'emergency repair capability in wartime, it is necessary to simulate this kind of environment and vigorously carry out the maintenance training of all kinds of rapid recovery equipment under emergency conditions.

Plugging training. For some oil and gas leakage, we can carry out some fast adhesive plugging simple process training, slight leakage, can practice using soap or clay plugging, serious, can practice using leak stopper, easy to repair cement plugging, etc., these can be used as emergency repair measures.

Transposition repair training. The so-called transposition repair, is to use their own parts transposition installation or change the installation position and direction, in order to restore the original function. For example, when two loaded wheels on one side of an armored vehicle are damaged and the other side is not damaged, the third loaded wheels on the intact side can be 
removed and installed on the damaged side; when the gear ring of the engine flywheel is affected by one-sided wear and tear, the gear ring can be installed and reused.

Short repair training. Short-circuit repair refers to the equipment of the hydraulic system, pneumatic system, fuel supply system and electrical equipment in the tubing, pipe or circuit for short connection, over the parts or circuits that have been faulty, the pipe or circuit will be directly connected to maintain certain functions. When a part surface or circuit can not be repaired in a short time, the use of short repair can effectively restore the other parts of the equipment function.

Demolition and repair training. That is, to carry out training on the method of replacing damaged assemblies or components from other equipment by disassembling parts of assemblies or components that can be used or have repairable value for the time being and replacing them with damaged assemblies or components so as to reassemble good equipment with damaged or discarded equipment.

"Simple measures " is a suitable method, the level of equipment recovery is low, limited to the temporary recovery of equipment in the absence of conditions, part of the capacity, but also no way out. When the battlefield is seriously short of all kinds of resources, grasping the "soil method" is a wartime equipment repair must have the ability.

\section{Virtual battlefield environment, virtual maintenance training to enhance the resilience of the battlefield.}

Virtual maintenance is an important research direction of virtual technology in recent years. The purpose is to show the maintenance environment and conditions on the computer by using computer simulation and virtual reality technology, so as to train the maintenance skills. It is mainly the artificial environment of three-dimensional information composed of computer software and hardware and various advanced sensors, that is, the three-dimensional environment of computer simulation. With the help of necessary equipment, users interact with objects in the virtual environment in a natural way and interact with each other, thus forming a special effect of vivid audio-visual and tactile integration. In order to generate feelings and experiences in the real environment. In the NCO's Vocational and technical education, virtual maintenance training can show obvious advantages.

Virtual maintenance training system can reproduce battlefield environment vividly, including combat background, battlefield scene, various weapons and equipment, and combatants. It creates a dangerous and nearly real three-dimensional battlefield environment through background generation and image synthesis. The trainees use three-dimensional helmet, data suit and data glove or three-dimensional glove. Uygur mouse operation sensor device can make or choose the corresponding action, input different disposal plan, experience different effect, and then like participating in actual combat, not only improve the ability of rush repair in wartime, but also exercise the technical and tactical level, rapid reaction ability and psychological endurance, compared with the conventional training methods, virtual Practical training has the characteristics of realistic environment, changeable scenes, strong pertinence, safety and economy, and strong controllability. It effectively solves the problems of not being able to feel the battlefield conditions, environment and resources in peacetime training, and greatly promotes the formation of sergeants'emergency repair capability in wartime.

Virtual maintenance training system breaks through the space and time constraints, realizes realistic equipment disassembly, fault maintenance and other operations, extracts existing equipment data, status data, test equipment performance. It can significantly improve the maintenance status of equipment, shorten the maintenance design time of equipment, reduce the loss caused by improper maintenance decision in advance, provide a more reliable maintenance model for rapid maintenance, and also can analyze and pre-treat the equipment fault, simulate the disassembly process. Predicting maintenance operation time, allocating maintenance resources, choosing maintenance tools, setting down disassembly sequence and estimating maintenance cost of equipment components, enhancing decision-making ability of maintenance at various stages of equipment life cycle, including maintainability design analysis, maintainability demonstration 
verification, maintenance process verification, maintenance training implementation, etc. The equipment wastage is reduced, the problems of insufficient training equipment and high training cost are effectively solved, and the teaching efficiency is greatly improved.

\section{Conclusion}

The training of non-commissioned officers'emergency repair ability in wartime equipment has become the top priority of the current non-commissioned officers' vocational and technical education, and has put forward higher requirements for us. We must constantly strengthen the concept, means, conditions and other aspects in order to meet the needs of the army.

\section{References}

[1] Gao.Ning:Discussion on maintenance and support of new armored equipment [J]. China military education, 2013 (4)

[2] B. Zhu: Sergeant education method, Vocational and technical education,2015 .

[3] Wang.Ting: TResearch methods of military education, China military education, 2012.

[4] Zhu.Tao: Research on equipment maintenance method . Military Equipment, 2010

[5] Tian Li: NCO curriculum design, Sergeant Education 2010.

[6] Ma.Ping: Research on virtual maintenance methods, Innovation science and technology, 2014. 